\title{
News
}

\section{International "School of Arrhythmology" in Kyrgyzstan.}

Abai Turdubaev ${ }^{1}$, Jonathan Lipton ${ }^{2}$

${ }^{1}$ Scientific Research Institute of Heart Surgery and Organ Transplantation, Bishkek, Kyrgyzstan

${ }^{2}$ Electrophysiology Clinic, Melbourne Hospital, Melbourne, Australia

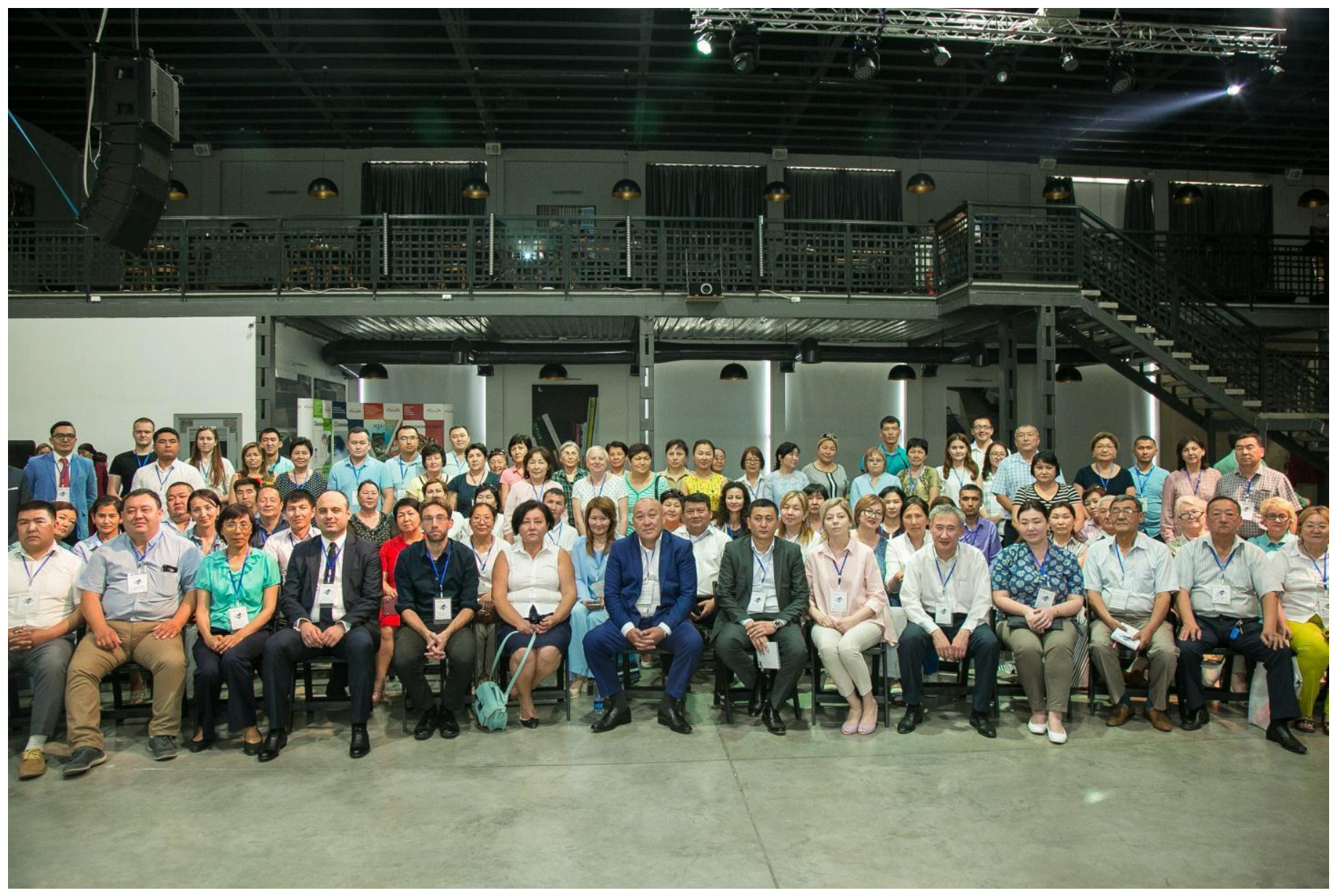

Address for Correspondence: Abai Turdubaev, SRI of Heart Surgery and Organ Transplantation, Togolok Moldo 1/3, Bishkek, Kyrgyzstan, turdubaev@gmail.com

Received: 10.08.2018 Accepted: 16.08.2018

Copyright@ Heart, Vessels and Transplantation 
For the first time in Kyrgyz Republic, the first scientific and international Arrhythmology School was organized by main cardiac surgery of Kyrgyzstan Scientific Research Institute of Organ Transplantation (SRIHSOT) with support of Ministry of Health. The conference Contemporary Methods of Arrhythmia Diagnosis and Treatment of Arrhythmias for Cardiologists and Family Physicians took place on 19.06.2018 in cultural center Asanbai.

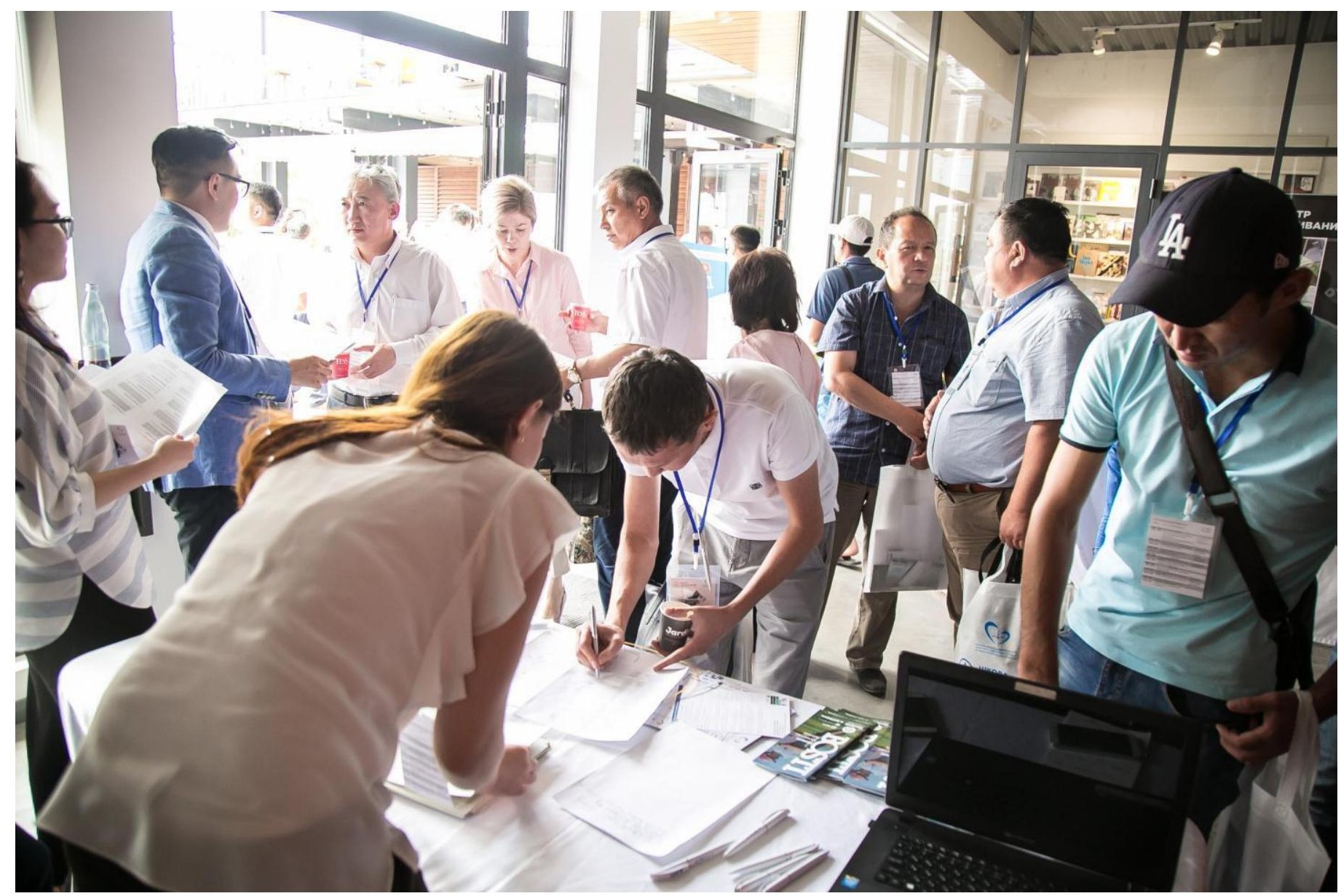

International conference was held with leading specialists from Australia - Jonathan Lipton (Electrophysiology Clinic, Melbourne Hospital, Melbourne, Australia), Kazakhstan (SRI of cardiology and internal medicine), Georgia - Roin Rekvava (High Technology Medical center) и Kyrgyzstan - Gulmira Kudaiberdieva (Center for Postgraduate Education and Scientific Research ). 


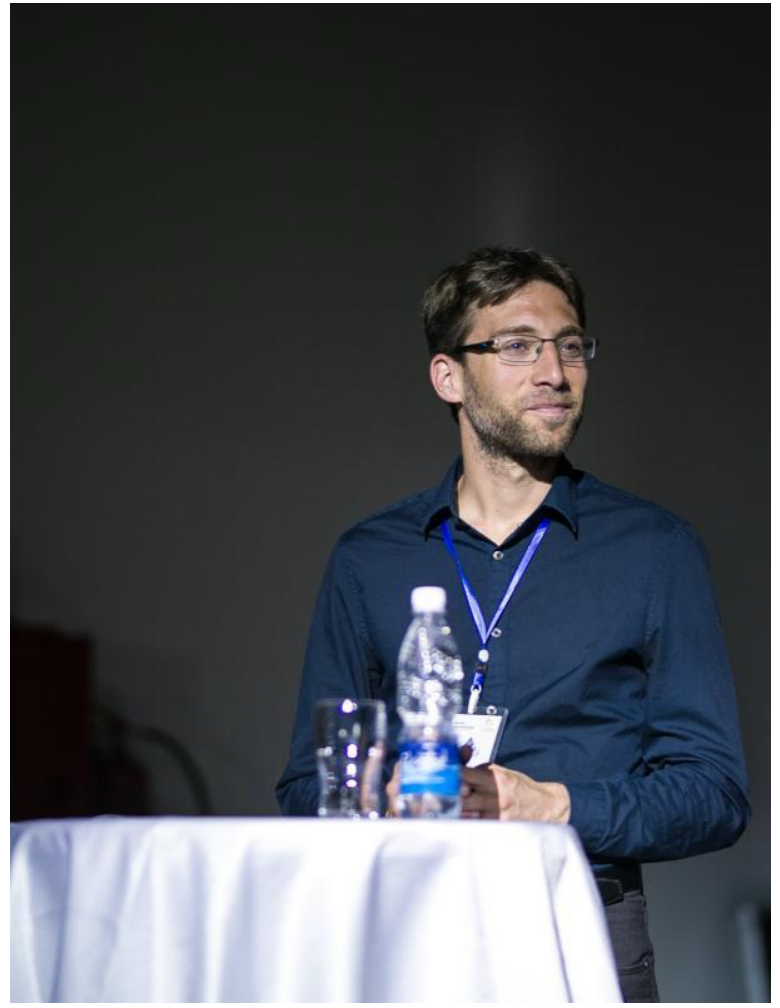

Jonathan Lipton (Australia)

Participants of international School of Arrhythmias included 150 cardiovascular surgeons, cardiologists, family physicians and anesthesiologists from 7 regions of our Republic and also Kazakhstan,

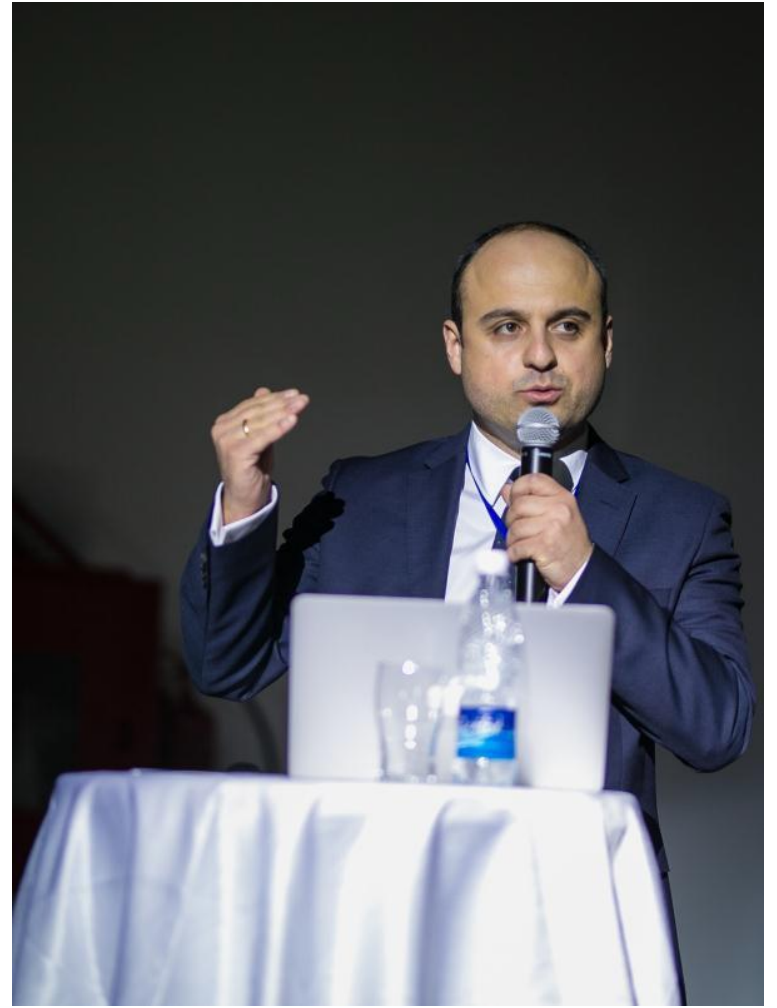

Roin Rekvava (Georgia, Kazakhstan)

who underwent course on diagnosis and treatment of arrhythmias according to modern recommendations and received certificates. 


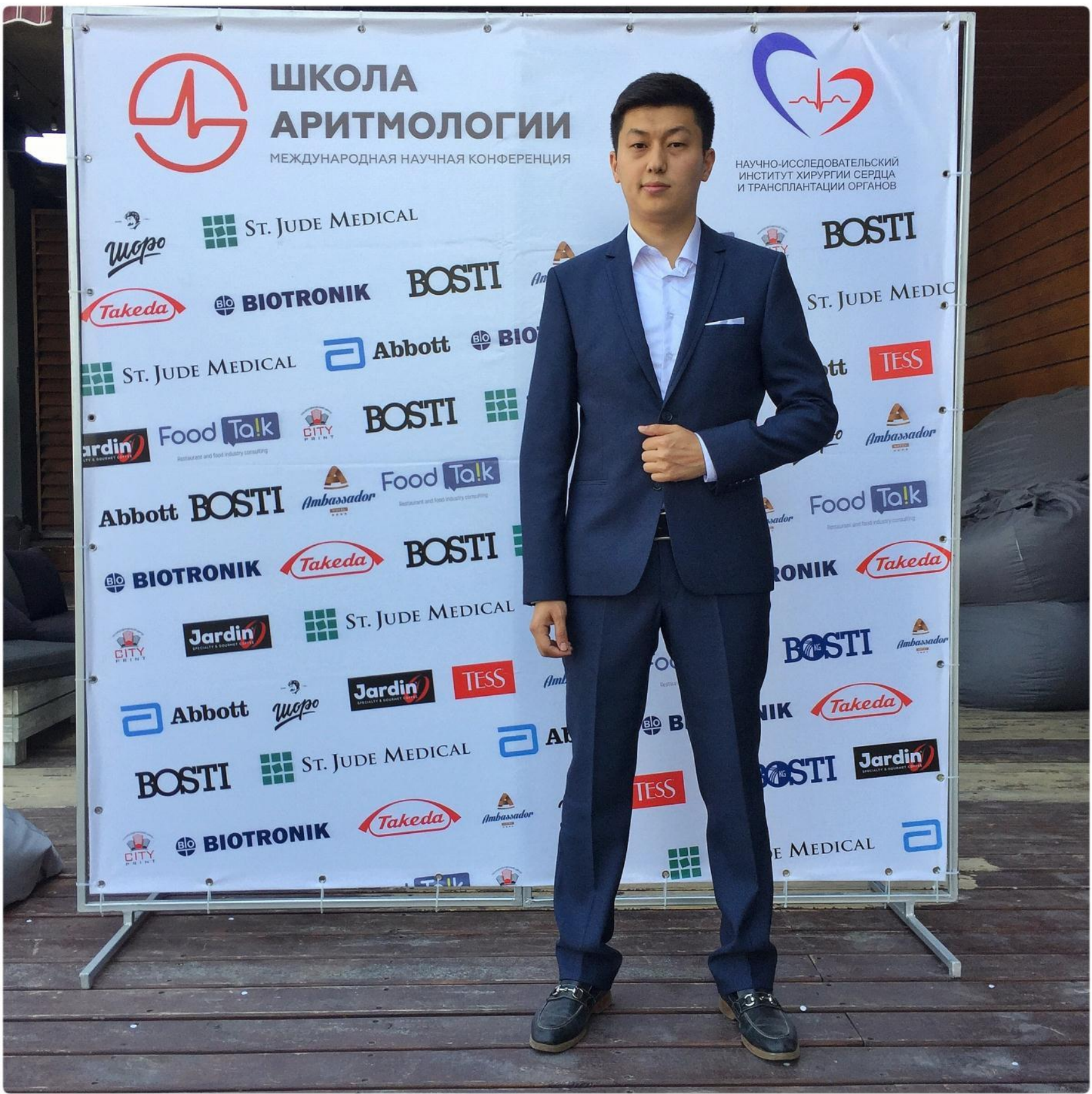

Director of School of Arrhythmias Abai Turdubaev (Kyrgyzstan) 
During School of arrhythmias, the actual treatment of complex arrhythmias and conduction issues of arrhythmology service development in disturbances that improve the quality of life of Kyrgyzstan and worldwide. New methods of patients were presented and discussed.

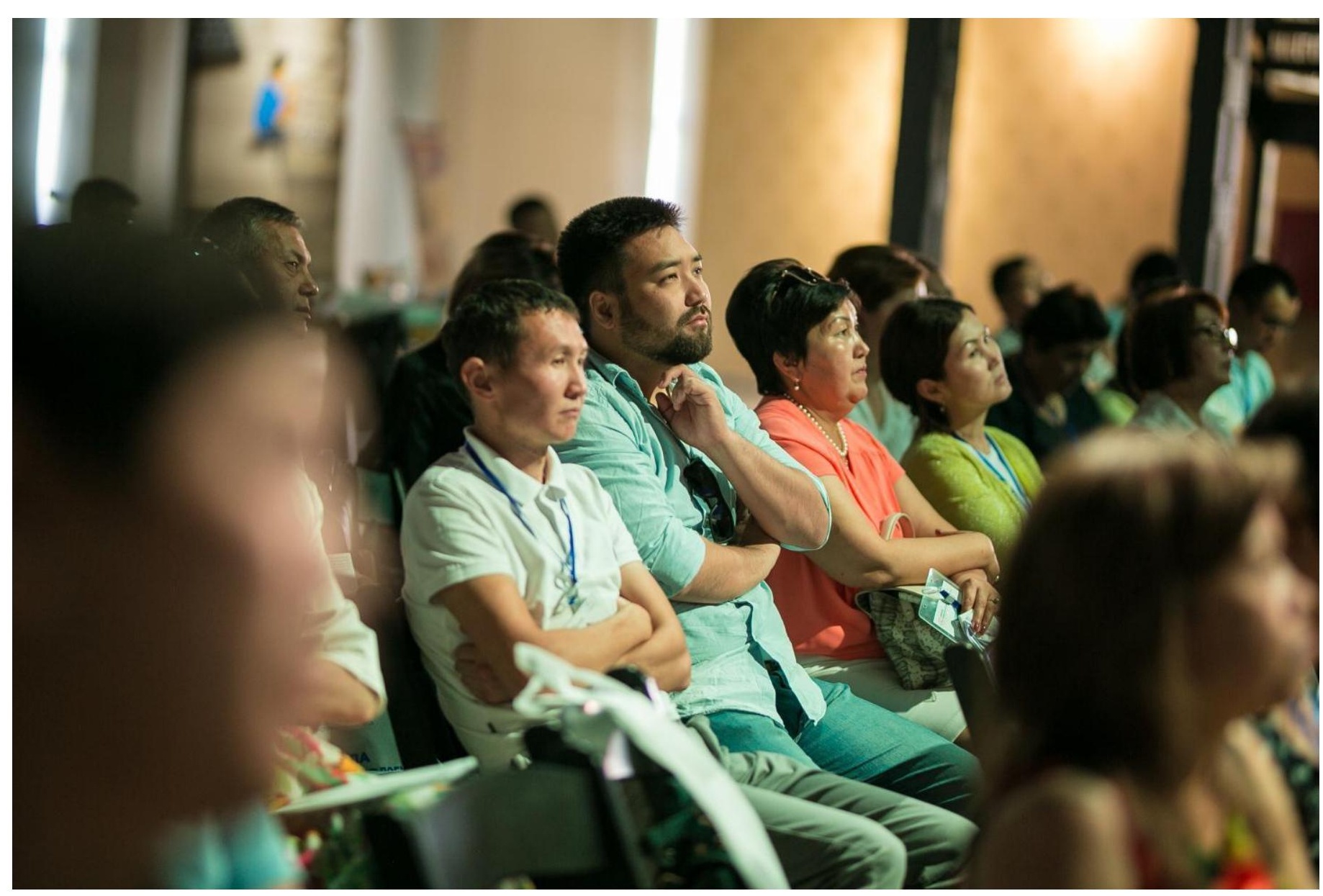

In frame of congress, there was an official opening ceremony and contest of arrhythmias management, the winner received main prize - two travel grants for participation in Russian National congress of cardiologists - 25-28 September, 2018, Moscow. 


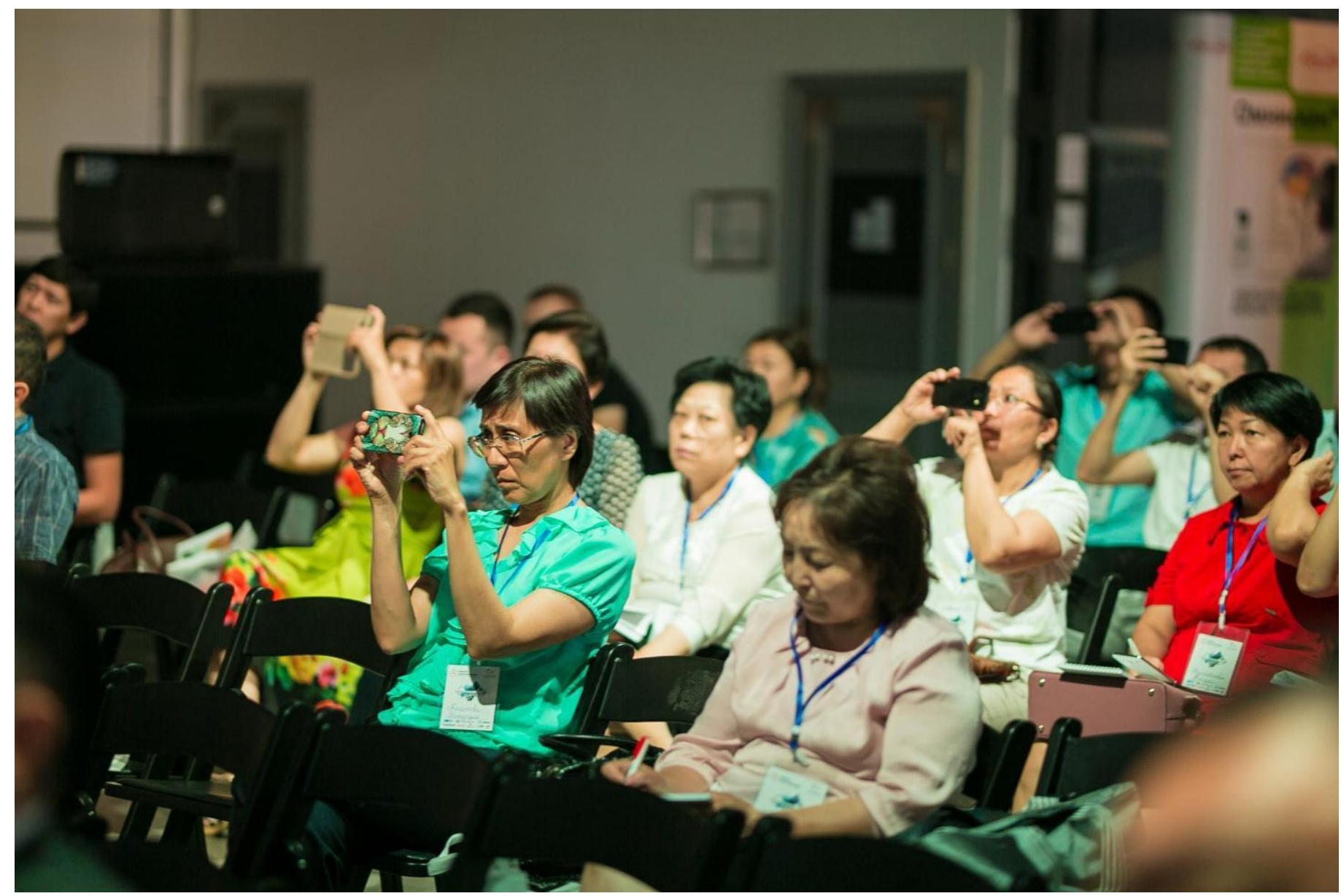

SRI of heart surgery and organ transplantation, being a leading organization on diagnosis and treatment of cardiovascular disease, in collaboration with Center for Postgraduate Education and Scientific Research and Eurasian Association of Cardiothoracic Surgeons plans to hold every year international scientific-practical conferences events aiming at development of educational and scientific potential of all specialists interested in contemporary diagnosis and treatment of various diseases of cardiovascular system. 